\title{
Investigation on Teardrop Connection of Rack Clad Building
}

\author{
Radin Md Mahirul Hoque ${ }^{1}$, Peng Zhang ${ }^{2}$, M. Shahria Alam ${ }^{3}$, Robert Tremblay ${ }^{4}$ \\ ${ }^{1}$ The University of British Columbia \\ 3333 University Way Kelowna, BC Canada V1V 1V7 \\ mahir10ce@gmail.com; ubcpengz@gmail.com \\ ${ }^{2,3}$ The University of British Columbia \\ 3333 University Way Kelowna, BC Canada V1V 1V7 \\ shahria.alam@ubc.ca; robert.tremblay@polymtl.ca \\ ${ }^{4}$ École Polytechnique de Montréal \\ Montreal, Quebec H3T 1J4, CA
}

\begin{abstract}
A rack clad building (RCB) is a kind of storage system where the raking forms part of the structure. The larger size of the RCB structure makes it dissimilar to the typical storage system. To enhance the lateral stability and the moment capacity in the unbraced down aisle direction, different types of connections are used in the rack clad building history. Teardrop connection which is one of the connection systems of the RCB, is a boltless connection where tabs used as connectors, are entered into the perforated hole of the cold formed column. The moment capacity, rotational stiffness, rotational capacity of the teardrop connection are the parameters that determine the efficiency in controlling the sway limitation in the down-aisle direction. There is limited research on the investigation of the mechanical behaviors and the design of teardrop connections. On this account, it is imperative to disclose the vital parameters related to the performance of the connector. This paper reviews the existing methods such as different types of experimental studies, finite element analysis, analytical model, component method which are used in determining the stiffness and the capacity of the connection. Finally, the influence of the geometric characteristics of the components such as thickness of the column, height of the beam, number of tabs, welding position of the beam to beam end connector, on the performance of the joint, has been presented in this paper.
\end{abstract}

Keywords: Storage rack, Teardrop connection, Tab connector, Cold-formed steel

\section{Introduction}

A rack-clad building (RCB), which is one kind of steel infrastructure, is used for storing goods on large scale. Even though the structural components and response under the seismic loading of the RCB are totally dissimilar to the conventional steel storage system, the popularity of RCB is increasing progressively. The RCB is comprised of the following components: upright (mainly known as a column), beam, beam end connector (boltless or bolt connection), pallet, bracing, baseplate which are manufactured from cold-formed steel. Two directions exist in RCB, one is cross-aisle (transverse direction), another one is down-aisle direction (longitudinal direction). The wellorganized storage capacity and adequate accessibility of the storage products to RCB, are the key attributes of this system. To meet these requirements, bracings are provided in the cross-aisle direction for the resistance of the lateral load (wind load or seismic load) and the down-aisle direction is kept free for products loading or unloading. Therefore, the connection of the beam-column joint is designed in such a way that, bracing is not needed in the longitudinal direction to resist any type of lateral loads. Considering this fact, the configuration and function of beamcolumn joint have extensive influence on the structural stability function.

The different types of connections for the beam-column joint are proposed, such as bolt connection, teardrop connections, etc. The teardrop connection, also known as beam end connector, is used more these days on account of having boltless connection (figure 1). The tab, a component of the connector, plays the role of the bolt. The thin column section has perforated slots, in which the tab of the connector is inserted into the hole and engaged the connection between the column and beam. It is difficult to have an idea of the structural response of RCB from a specific analytical methodology under different load conditions because there are varieties types of column sections and different types of beam end connector. In this regard, experimental studies are needed to evaluate the response of the structure for a particular configuration, joint 
types, and shapes. However, these repeated experiments would be expensive. Therefore, finite element modeling is the best solution to replace the need for the repeated experiments. There is a limited number of numerical studies on the RCB and the steel beam-column joint in previous years[2-7] and some experimental studies on the joint connection of RCB [8-11], but few studies have been done on the response of teardrop connections of RCB. This paper presents a comprehensive review on the teardrop connection, summarizing the methods for the determination of the properties of the connection, and describes the parametric studies.

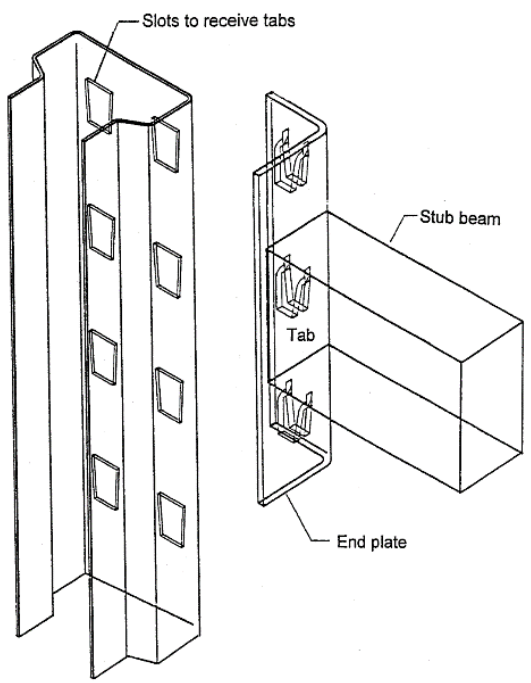

Fig. 1: components of the teardrop connection. [1]

\section{Experimental Study}

In this section, the previous detailed experimental investigations are described.

\subsection{Single Cantilever Test}

The single cantilever test method, described in [12] is used to determine the rotational stiffness of the connection. In past years, to evaluate the strength attributes of the connection, Kamal M. Bajoria et al. [5], Dumbrava \& Cerbu [13] and Vujanac et al. [14] executed the single cantilever test method. In figure 2, the details of the experimental setup are shown. Both ends of the stub column are attached to a rigid frame. One end of the box beam is associated with the stub column by use of a beam end connector and another end is kept unconnected. The lateral movement and twisting of the box beam are constrained by providing proper restrains and only the free end of the beam is allowed to move in the vertical direction. To obtain the beam-column failure scenario, the initial applying load should be $10 \%$ of the estimated failure load, and then the load is applied step by step at $400 \mathrm{~mm}$ from the face of the column by an actuator that rests on the free end of the beam. In the last few years, there were some single cantilever experiments where the distance between the loading point and the column face varied from the $400 \mathrm{~mm}$ distance. Estate \& Division [15] loaded the beam by applying load at $200 \mathrm{~mm}$ and K. M. Bajoria \& Talikoti [3] considered the loading distance $900 \mathrm{~mm}$ from the free surface of the column. In single cantilever test, the bending moment caused by the applied load and corresponding rotation are measured. To calculate the corresponding rotation of the beam, mainly displacement transducer or inclinometer are used for the measurement. In the case of the transducer, two transducers are required where one is fixed to the top of the beam to measure the movement of the upper beam end connector and another is fixed to the bottom of the beam to measure the movement of the bottom end connector. From the differences between these two readings, the rotational angle is evaluated. Instead of transducers, an inclinometer can also be used for angle measurement. 


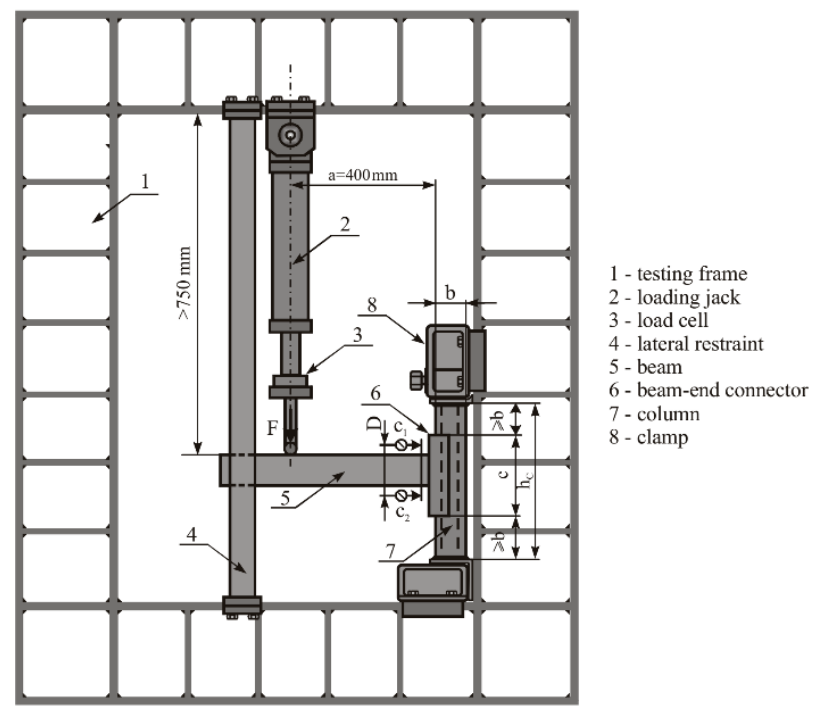

Fig. 2: Single Cantilever test setup. [14]

\subsection{Double Cantilever Test}

The double cantilever test is almost opposite to the single cantilever test setup. In this system, two box beams connected to the opposite faces of the column and one stub column are considered. One end of the box beam rests on the roller support and the other end is connected to the column with the help of beam end connectors. Both ends of the stub column are free and the load is applied vertically by loadcell on the top of the column. Proper restraints are used to restrain the lateral movement of the beam. For the measurement of the rotation of the beam, an inclinometer similar to the single cantilever test can be used [6]. Alternatively, four displacement transducers can also be used [3]. Though the double cantilever test is not included in any design code, K. M. Bajoria \& Talikoti [3] found that the double cantilever test is more effective than the single cantilever test. In table 1 , the comparison between the single cantilever and double cantilever is showed. It shows that deflection, bending moment from the double cantilever test are closer to full-scale frame test than the single cantilever test. A schematic diagram of double cantilever test setup from the experiment done by Shah et al. [6] is shown in figure 3.

Table 1: Comparison between Single cantilever and double cantilever. [3]

\begin{tabular}{|c|c|c|c|c|c|c|}
\hline & \multicolumn{2}{|c|}{ ANSYS model Stiffness from } & \multicolumn{2}{|c|}{ Full Scale Test } & \multirow[b]{2}{*}{$\begin{array}{l}\text { Differences } \\
\text { between } \\
\text { single } \\
\text { cantilever } \\
\text { and full- } \\
\text { scale test }\end{array}$} & \multirow[b]{2}{*}{$\begin{array}{l}\text { Differences } \\
\text { between } \\
\text { double } \\
\text { cantilever } \\
\text { and full- } \\
\text { scale test }\end{array}$} \\
\hline & $\begin{array}{l}\text { Single } \\
\text { Cantilever }\end{array}$ & $\begin{array}{l}\text { Double } \\
\text { cantilever }\end{array}$ & Left span & Right Span & & \\
\hline $\begin{array}{l}\text { BM at center } \\
\text { of Span }(\mathrm{kN}- \\
\text { m) }\end{array}$ & 2.086 & 2.03 & 2.053 & 2.046 & $2.00 \%$ & $0.733 \%$ \\
\hline $\begin{array}{l}\text { Deflection at } \\
\text { center } \\
\text { span }(\mathrm{mm})\end{array}$ & 3.80 & 3.679 & 3.689 & 3.725 & $2.50 \%$ & $0.755 \%$ \\
\hline
\end{tabular}




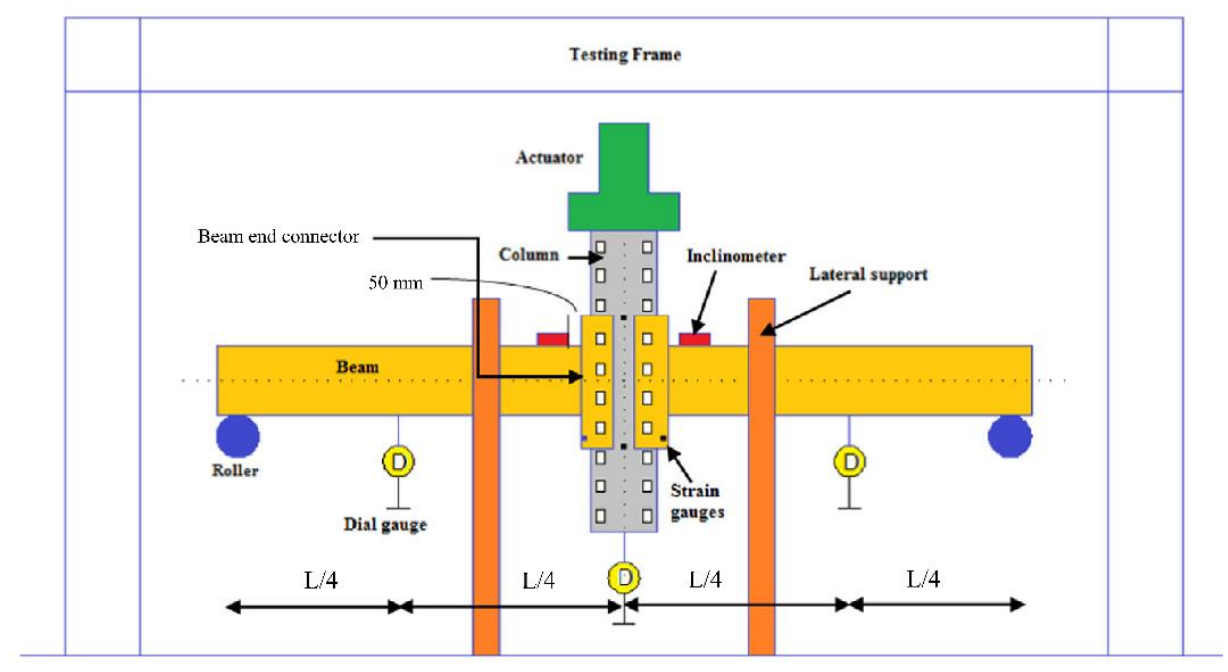

Fig. 3: Double Cantilever test setup. [6]

\subsection{Cyclic Testing:}

There are several experiments related to cyclic loading alongside monotonic loading to evaluate the features in seismic zones. Bernuzzi \& Castiglioni [16] exercised cycling testing to make parametric comparisons with joints for traditional steelframed buildings in the form of hysteresis loops. There are also several cyclic testing of RCB, considering the single cantilever test setup. Yin et al. [17] investigated the behavior of speed-lock connections with bolts under monotonic and cyclic loading. The research examined the improvement of the energy dissipation capabilities for using a different combination of bolts in joint and the pinching behavior in the hysteresis responses. From cyclic testing, Shariati et al. [18] developed a new connection system with a bolt that improves the strength, stiffness, failure attributes to the connections. Gusella, Lavacchini, et al. [11] and Lyu et al. [19] did cyclic testing to investigate the response of the joint in seismic zones. Jovanović et al. [7] also proposed a constitutive model which could be used for the simulation of the cyclic fatigue and pinching behavior of RCB.

\section{Finite Element Modeling}

There are a lot of varieties of column sections, beam sizes, different shapes of slots opening in the column, position of the beam end connectors, etc. which have made it difficult to predict the behavior of RCB by any analytical model. Thus, all the modern codes on RCB, suggest doing experiments to inspect the desired behavior of a particular configuration of RCB [6]. A huge number of test samples are needed to do research by performing experiments which would be expensive. Finite element modelling is the alternative solution to reduce this cost. There are lots of commercially available finite element software to do finite element analysis. RCB teardrop connection has mainly four components such as upright (column), beam, beam end connector, tabs. Normally material properties needed for the modeling are obtained from experimental coupon testing. Bilinear elasto-plastic material and geometric nonlinearity are incorporated in the modeling. Shell element with strain hardening properties is used for the modeling of upright (column), beam and beam end connector. The tab is modeled using Solid element to achieve the proper response of the structure. Solid element mainly causes the convergence problem while computational running but presents a real scenario of the behavior of the tabs' response. Proper surface interaction modelling is especially important for replicating the contact behavior between the tabs and the column. Shah et al. [6] showed a detail of the contact behavior. The nonlinear contact interaction occurs between the surface of the tab and the surface of the opening slots of the column which is known as normal hard contact. Other surface interactions are considered as tangential frictionless contact. In [6], a detailed concept of this surface interaction is given. A proper boundary condition should be integrated into the model. An efficient meshing system of the modeling has an important role in validating the model with the experiment. As the failure occurs at the beam-column joint, high-density meshing is preferred at the beam end connector and the tabs. The experimental loading protocol is followed in the finite element modeling to 
replicate the real response. K. M. Bajoria \& Talikoti [3] and Kamal M. Bajoria et al. [5] used ANSYS and Shah et al. [6] used ABAQUS to model the finite element model of teardrop connection.

\section{Analytical and Mechanical Model:}

Mechanical model and analytical model are one of the methods to evaluate the mechanical behavior of teardrop connection. Mechanical method based on the component method is very efficient to investigate the mechanical behavior of the joint with the help of rigid and flexible components which are calculated from the values attained from the empirical analysis [20]. Zhao et al. [21] introduced a mechanical model by which initial rotational stiffness of the teardrop connection of RCB could be predicted. This initial rotational stiffness came from five basic deformable components (figure 4): tab in bending(tb), upright wall in bearing ( $\mathrm{cwc}$ ), and upright wall in bending (cwb), beam-end-connector in bending and shear (bcb), upright web in shear (cws).

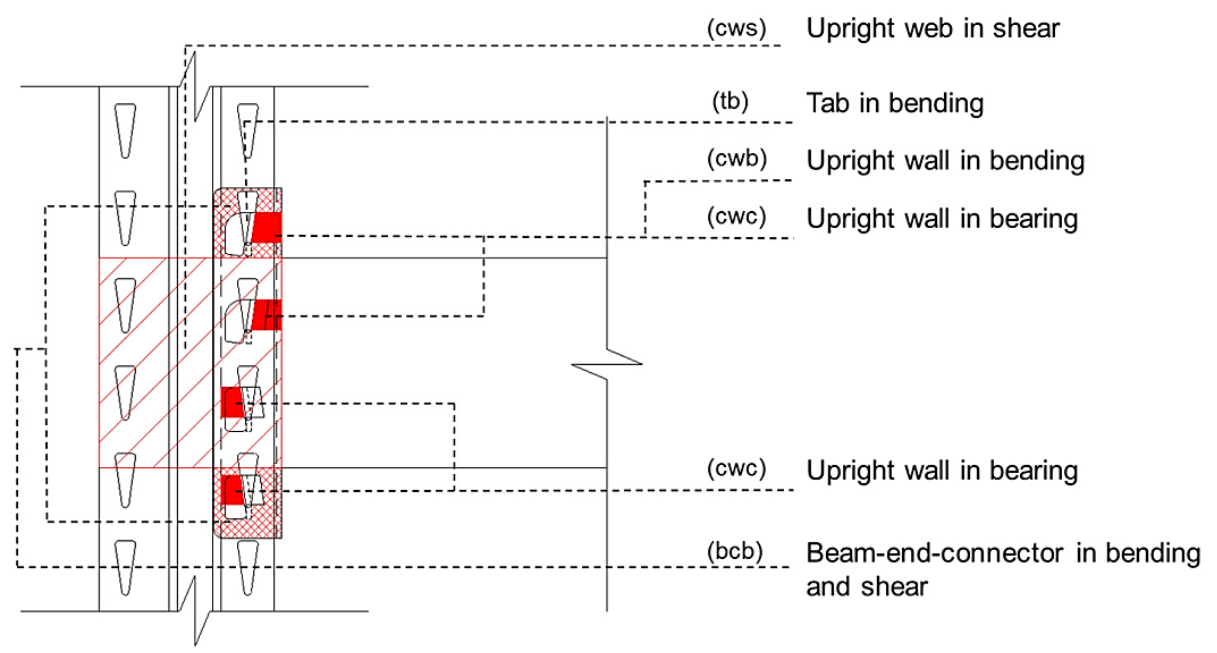

Fig. 4: Components of beam to upright tab connection. [21]

The proposed initial stiffness $k_{0}$ is given in equation (1),

$$
k_{0}=\frac{1}{\frac{1}{k_{t-\varphi}}+\frac{1}{k_{c w s}-\varphi}}
$$

where, $k_{0}$ is the initial rotational stiffness, $k_{c w s}$ is the stiffness of the components independent of the tab rows (upright web in shear) and $k_{t-\varphi}$ is the equivalent overall rotational stiffness which comes from equation (2),

Here,

$$
k_{t-\varphi}=\sum_{i=1}^{n} k_{i}^{*} L_{i}^{2}
$$

stiffness of equivalent extensional spring $k_{i}^{*}$ (" $i$ " indicates the number of tab row) relating to the tab rows and $L_{i}$ represents the lever arm of each stiffness of equivalent extensional spring. $k_{i}^{*}$ is given in equation,

$$
k_{i}^{*}=\frac{1}{\frac{1}{k_{t b, i}}+\frac{1}{k_{c w c, i}}+\frac{1}{k_{c w b, i}}+\frac{1}{k_{b c b, i}}}
$$

The initial rotational stiffness described in equation (1) can be understood from figure 5, where details of the procedure are given. The full range moment-roation curve for the teardrop connection could be constructed with the help of the basis of this proposed model. 


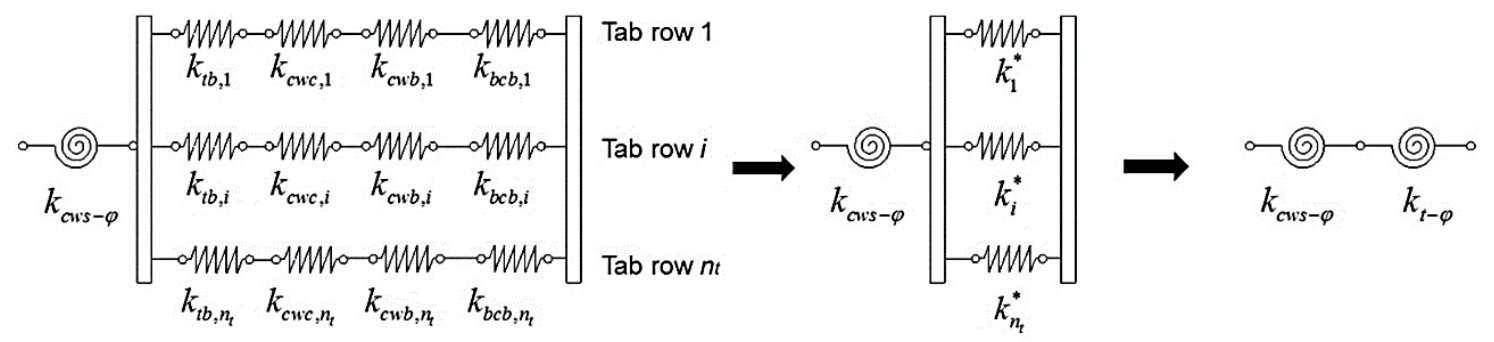

Fig. 5: Procedure for evaluating the initial rotational stiffness.[21]

Gusella et al. [22] using component method, introduced a mechanical model which helps to evaluate the ultimate bending moment of the connection and to investigate the failure mechanism of individual component. This proposed model would help to improve the performance of the joint by finding the individual contribution of each component in teardrop connection strength and redesign could be performed according to the investigation. The mechanical models were validated with previous experiments and the validations showed the good agreement between the proposed model and the experiment.

Prabha et al. [23] introduced two analytical models to assess the parametric investigation on the teardrop connection. Frye \& Morris [24] developed a non-dimensional polynomial model to construct the moment-rotation curve for a particular joint of structural steel frame connection. Prabha et al. [23] proposed a polynomial model based on Frye and Morris model which could predict the initial stiffness of the joint by taking consideration of column thickness, beam depth, connector depth. For any elastic analysis of the connection, the stiffness from the prescribed model is useful. Prabha et al. [23] also proposed a power model to predict the ultimate moment capacity of teardrop connection.

\section{Parametric Studies:}

\subsection{Effect of Upright Thickness:}

The thickness of the column has an important role on the performance of the teardrop connection. Comprehensive studies were performed to investigate the effect of column thickness on the joint strength by keeping other parameters (beam depth, number of tabs) unchanged for monotonic load. Researches showed that the rotational stiffness and bending strength of the connection are proportional to the thickness of the column [6,14,15,18,19,25]

The thickness effect of the column on bending strength under cyclic test was also investigated by Lyu et al. [18] and Shariati et al. [19]. The relationship between the connector resistance capacity and the thickness of the upright for cyclic loading is similar behavior to monotonic loading.

\subsection{Effect of Beam Height on the Connection Behavior:}

The height of the beam has also influential impact on the moment resisting capacity of the teardrop connection.

Zhao et al. [25] showed that $120 \mathrm{~mm}$ beam depth had more 14\% average initial stiffness and $4 \%$ more bending moment capacity than $105 \mathrm{~mm}$ beam depth but the additional increase of depth of the beam from $120 \mathrm{~mm}$ to $145 \mathrm{~mm}$, did not maintain the same pattern. The moment capacity was improved but the average initial stiffness was unchanged comparing with the $120 \mathrm{~mm}$ depth beam.

Vujanac et al. [14] found that changing height of the beam from $100 \mathrm{~mm}$ to $120 \mathrm{~mm}$, the rotational stiffness and bending strength of the connection were increased by $20 \%$ but when changing the depth from $100 \mathrm{~mm}$ to $140 \mathrm{~mm}$, increased rate of rotational stiffness and bending strength were not the same as before. The bending strength and rotational stiffness were increased by $40 \%$ and $70 \%$ respectively. So, the larger beam depth of the connection obtains the higher moment resting capacity and initial rotational stiffness.

\subsection{Influence of Beam End Connector:}

Failure mode and capacity of the connection depend on the geometric properties of the beam end connector. In Shariati et al. [18], influence of the variety of thickness of the end connector was investigated. A comparison between $4 \mathrm{~mm}$ and 2 $\mathrm{mm}$ thickness of the beam end connector was shown under the failure condition, where the tabs for $2 \mathrm{~mm}$ thickness showed 
more distorted than $4 \mathrm{~mm}$ thickness. Moreover, reducing the thickness from $4 \mathrm{~mm}$ to $2 \mathrm{~mm}$, the resisting moment capacity and rotational stiffness of the connection reduced by $18 \%$ and $49 \%$ respectively.

Another comparative study was made between $4 \mathrm{~mm}$ and $6 \mathrm{~mm}$ thickness of the end connector. The capacity of the 6 $\mathrm{mm}$ thick connection was increased and the deformation of the components of the beam end connector was less compared to the $4 \mathrm{~mm}$ thickness. $6 \mathrm{~mm}$ thickness comparing with $2 \mathrm{~mm}$ thickness increased the moment capacity by $14 \%$ and improved the rotational stiffness by $49 \%$.

Moreover, the number of tabs in the beam end connector has impact on the moment capacity of the connection. The number of tabs in the beam end connector is proportional to the capacity of the connection $[14,25]$.

\subsection{Influence of the Welding Position of the Beam To Beam End Connector:}

Jovanović et al. [7] highlighted the purpose of three different connected positions (beam welded at the top, middle, bottom of the beam end connector) of the stub beam to the beam end connector by welding.

Shah et al. [6] did a parametric study on failure mode and strength capacity of three welding positions of the beam to the beam end connector. In figure 6 , failure mode and the stress distribution of the three different beam positions are shown. Beam welded at the top, showed premature failure of the connection, and faced significantly nonlinear compressive stress distribution in the upper zone. The middle welding position showed less critical stress distribution than the upper welding position, but the bottom welding position showed more uniform stress distribution than other two in both tension and compression zone. Shah et al. [6] also made a comparative study for the strength and stiffness of the three-welding positions of beam which is shown in table 2. Keeping other parameters unchanged, the strength and rotational stiffness were increased when the welding position of the beam to the connector moved from top to bottom.

\section{Conclusion:}

To ease the loading-unloading of the stored goods, the down-aisle direction of the RCB is kept unbraced. Therefore, lateral stability in the down-aisle direction is controlled by the stiffness of the beam-column joint and the stiffness of the base plate connected to column.
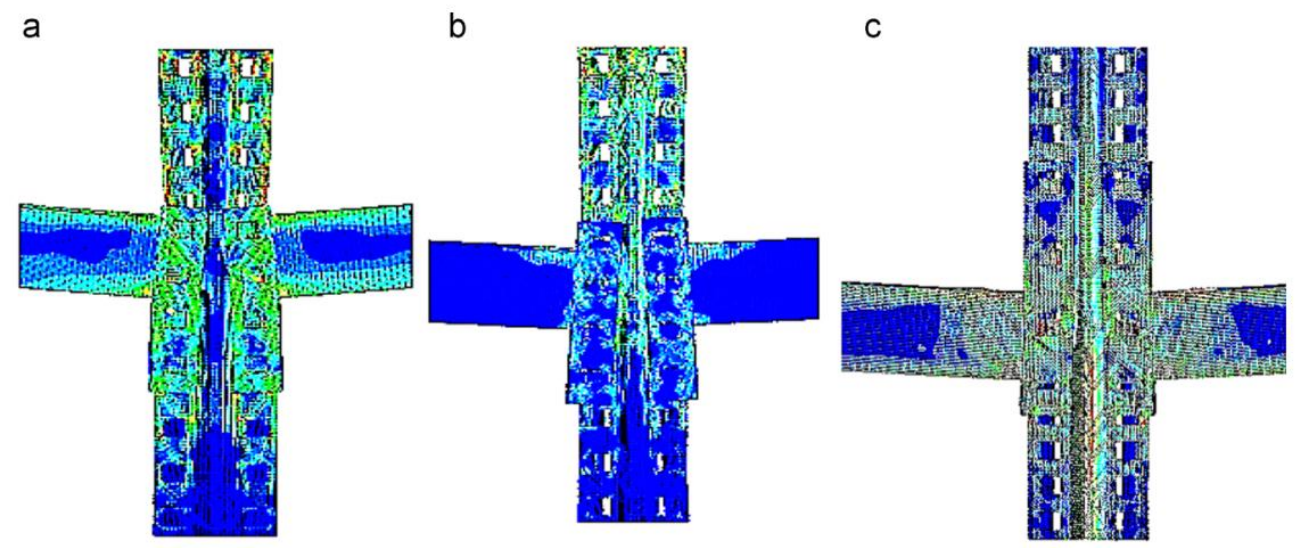

Fig. 6: Failure modes of the specimens with various welding positions of beam to the beam end connector (a) Top welding (b) middle welding (c) Bottom welding. [6]

Table 2: Strength and stiffness of the specimens with various welding positions of beam to the beam end connector. [6]

\begin{tabular}{|c|c|c|}
\hline specimen & Ultimate moment capacity (kNm) & Rotational stiffness (kNm/rad) \\
\hline Top welding position & 1.73 & 23.28 \\
\hline Middle welding position & 2.21 & 29.8 \\
\hline Bottom welding position & 2.81 & 55.04 \\
\hline
\end{tabular}


The type of the beam-column joint connection and their structural design are very important for the stability of the RCB in unbraced direction. Teardrop connection is getting popular day by day because of easy to connect to the perforated column by means of different types of mechanical devices such as tabs, hooks. The determination of structural performance of RCB using a specific methodology is difficult to measure because of different types of geometric shapes, sizes of the beam, column, tabs. Moment resistance capacity, rotational stiffness, rotational capacity of the connection are the prime factors to evaluate the performance of the teardrop connection under different load conditions. There are several methods to determine these: experimental method, finite element method, analytical method, component method, etc.

This paper summarized the whole shebang of teardrop connections, presented a comprehensive review of the methods for determining the prime factors of the connection. Finally, the parametric studies are presented here from previous research. The following summary can be said from this study:

- The moment capacity and the rational capacity of the teardrop connection are proportional to the thickness of the column.

- The increased height of the beam normally increases the bending strength and the initial stiffness of the connection but sometimes bending strength or initial stiffness don't follow this trend.

- The thickness of the beam end connector and the number of the tabs in the connector are proportional to the strength of the connection.

- The investigation showed that the welding position of the beam to the beam end connector has influence on the stiffness and the moment capacity of the connection. Bottom welding position of the beam shows more effective than other welding positions (top position, middle position) for the strength and the capacity of the connection.

\section{Reference}

[1] F. D. Markazi, R. G. Beale, and M. H. R. Godley, "Numerical modelling of semi-rigid boltless connectors," Comput. Struct., vol. 79, no. 26-28, pp. 2391-2402, 2001, doi: 10.1016/S0045-7949(01)00058-X.

[2] A. M. S. Freitas, M. S. R. Freitas, and F. T. Souza, "Analysis of steel storage rack columns," J. Constr. Steel Res., vol. 61, no. 8, pp. 1135-1146, 2005, doi: 10.1016/j.jcsr.2005.02.004.

[3] K. M. Bajoria and R. S. Talikoti, "Determination of flexibility of beam-to-column connectors used in thin walled coldformed steel pallet racking systems," Thin-Walled Struct., vol. 44, no. 3, pp. 372-380, 2006, doi: 10.1016/j.tws.2006.01.007.

[4] A. L. Y. Ng, R. G. Beale, and M. H. R. Godley, "Methods of restraining progressive collapse in rack structures," Eng. Struct., vol. 31, no. 7, pp. 1460-1468, 2009, doi: 10.1016/j.engstruct.2009.02.029.

[5] K. M. Bajoria, K. K. Sangle, and R. S. Talicotti, "Modal analysis of cold-formed pallet rack structures with semi-rigid connections," J. Constr. Steel Res., vol. 66, no. 3, pp. 428-441, 2010, doi: 10.1016/j.jcsr.2009.10.005.

[6] S. N. R. Shah, N. H. Ramli Sulong, R. Khan, M. Z. Jumaat, and M. Shariati, "Behavior of Industrial Steel Rack Connections," Mech. Syst. Signal Process., vol. 70-71, pp. 725-740, 2016, doi: 10.1016/j.ymssp.2015.08.026.

[7] Đ. Jovanović, D. Žarković, V. Vukobratović, and Z. Brujić, "Hysteresis model for beam-to-column connections of steel storage racks," Thin-Walled Struct., vol. 142, no. May, pp. 189-204, 2019, doi: 10.1016/j.tws.2019.04.056.

[8] C. Aguirre, "Seismic behavior of rack structures," J. Constr. Steel Res., vol. 61, no. 5, pp. 607-624, 2005, doi: 10.1016/j.jcsr.2004.10.001.

[9] C. Bernuzzi, N. Draskovic, and M. Simoncelli, "European and United States approaches for steel storage pallet rack design. Part 2: Practical applications," Thin-Walled Struct., vol. 97, pp. 321-341, 2015, doi: 10.1016/j.tws.2015.08.011.

[10] C. Bernuzzi, A. Gobetti, G. Gabbianelli, and M. Simoncelli, "Unbraced pallet rack design in accordance with European practice-Part 1: Selection of the method of analysis," Thin-Walled Struct., vol. 86, pp. 185-207, 2015, doi: 10.1016/j.tws.2014.06.015.

[11] F. Gusella, G. Lavacchini, and M. Orlando, "Monotonic and cyclic tests on beam-column joints of industrial pallet racks," J. Constr. Steel Res., vol. 140, pp. 92-107, 2018, doi: 10.1016/j.jcsr.2017.10.021.

[12] B. Standard, "Steel static storage systems - Adjustable pallet racking systems-Principles for structural design," Bs En, vol. 15512, p. 15512, 2009.

[13] F. Dumbrava and C. Cerbu, "Experimental study on the stiffness of steel beam-to-upright connections for storage 
racking systems," Materials (Basel)., vol. 13, no. 13, 2020, doi: 10.3390/ma13132949.

[14] R. Vujanac, N. Miloradović, S. Vulović, and A. Pavlović, "A comprehensive study into the boltless connections of racking systems," Metals (Basel)., vol. 10, no. 2, 2020, doi: 10.3390/met10020276.

[15] D. I. Estate and B. Division, "ko," vol. 28, no. 1, pp. 57-87, 1997.

[16] C. Bernuzzi and C. A. Castiglioni, "Experimental analysis on the cyclic behaviour of beam-to-column joints in steel storage pallet racks," Thin-Walled Struct., vol. 39, no. 10, pp. 841-859, 2001, doi: 10.1016/S0263-8231(01)00034-9.

[17] L. Yin, G. Tang, M. Zhang, B. Wang, and B. Feng, "Monotonic and cyclic response of speed-lock connections with bolts in storage racks," Eng. Struct., vol. 116, pp. 40-55, 2016, doi: 10.1016/j.engstruct.2016.02.032.

[18] M. Shariati, M. M. Tahir, T. C. Wee, S. N. R. Shah, A. Jalali, M. M. Abdullahi, M. Khorami, "Experimental investigations on monotonic and cyclic behavior of steel pallet rack connections," Eng. Fail. Anal., vol. 85, no. December 2016, pp. 149-166, 2018, doi: 10.1016/j.engfailanal.2017.08.014.

[19] Z. J. Lyu, M. Wu, Y. X. Huang, Y. M. Song, and X. Cui, "Assessment of the dynamic behavior of beam-to-column connections in steel pallet racks under cyclic load: Numerical investigation," Adv. Civ. Eng., vol. 2018, 2018, doi: $10.1155 / 2018 / 9243216$.

[20] C. Daz, P. Mart, M. Victoria, and O. M. Querin, "Review on the modelling of joint behaviour in steel frames," J. Constr. Steel Res., vol. 67, no. 5, pp. 741-758, 2011, doi: 10.1016/j.jcsr.2010.12.014.

[21] X. Zhao, L. Dai, T. Wang, K. S. Sivakumaran, and Y. Chen, "A theoretical model for the rotational stiffness of storage rack beam-to-upright connections," J. Constr. Steel Res., vol. 133, no. March 2018, pp. 269-281, 2017, doi: 10.1016/j.jcsr.2017.02.014.

[22] F. Gusella, M. Orlando, A. Vignoli, and K. Thiele, "Flexural Capacity of Steel Rack Connections Via The Component Method," Open Constr. Build. Technol. J., vol. 12, no. 1, pp. 90-100, 2018, doi: 10.2174/1874836801812010090.

[23] P. Prabha, V. Marimuthu, M. Saravanan, and S. Arul Jayachandran, "Evaluation of connection flexibility in cold formed steel racks," J. Constr. Steel Res., vol. 66, no. 7, pp. 863-872, 2010, doi: 10.1016/j.jcsr.2010.01.019.

[24] M. J. Frye and G. A. Morris, "Reply: Analysis of flexibly connected steel frames," Can. J. Civ. Eng., vol. 3, no. 2, pp. 352-352, 1976, doi: 10.1139/176-034.

[25] X. Zhao, T. Wang, Y. Chen, and K. S. Sivakumaran, "Flexural behavior of steel storage rack beam-to-upright connections," J. Constr. Steel Res., vol. 99, pp. 161-175, 2014, doi: 10.1016/j.jcsr.2014.04.007.

[26] Đ. Jovanović, D. Žarković, V. Vukobratović, and Z. Brujić, "Hysteresis model for beam-to-column connections of steel storage racks," Thin-Walled Struct., vol. 142, no. April, pp. 189-204, 2019, doi: 10.1016/j.tws.2019.04.056. 